University of Nebraska - Lincoln

DigitalCommons@University of Nebraska - Lincoln

2010

\title{
Monotonic and cyclic short beam shear response of 3D woven composites
}

T. R. Walter

University of Florida

G. Subhash

University of Florida, Subhash@ufl.edu

University of Florida

C. F. Yen

US Army Research Laboratory-Survivability Materials Branch

Follow this and additional works at: https://digitalcommons.unl.edu/usarmyresearch

Part of the Operations Research, Systems Engineering and Industrial Engineering Commons

Walter, T. R.; Subhash, G.; University of Florida; and Yen, C. F., "Monotonic and cyclic short beam shear response of 3D woven composites" (2010). US Army Research. 158.

https://digitalcommons.unl.edu/usarmyresearch/158

This Article is brought to you for free and open access by the U.S. Department of Defense at DigitalCommons@University of Nebraska - Lincoln. It has been accepted for inclusion in US Army Research by an authorized administrator of DigitalCommons@University of Nebraska - Lincoln. 


\title{
Monotonic and cyclic short beam shear response of 3D woven composites
}

\author{
T.R. Walter ${ }^{\mathrm{a}}$, G. Subhash ${ }^{\mathrm{a}, *}$, B.V. Sankar ${ }^{\mathrm{a}}$, C.F. Yen ${ }^{\mathrm{b}}$ \\ ${ }^{a}$ Mechanical and Aerospace Engineering, University of Florida, Gainesville, FL 32611, USA \\ ${ }^{\mathrm{b}}$ US Army Research Laboratory-Survivability Materials Branch, AMSRD-ARL-WM-MD, Aberdeen Proving Ground, MD 21005-5069, USA
}

\section{A R T I C L E I N F O}

\section{Article history:}

Received 20 January 2010

Received in revised form 11 June 2010

Accepted 31 August 2010

Available online 6 September 2010

\section{Keywords:}

A. Textile composites

B. Delamination

Inter-laminar shear strength

C. Damage tolerance

\begin{abstract}
A B S T R A C T
Monotonic, multi-step and cyclic short beam shear tests were conducted on 2D and 3D woven composites. The test results were used to determine the effect of z-yarns on the inter-laminar shear strength as well as the multi-loading behavior. The presence of z-yarns was found to affect not only the inter-laminar shear strength of the composite but also the behavior of the composite beyond the elastic limit. Microscopic examination of the damaged specimens revealed large delamination cracks in 2D woven composites while delamination cracks were hindered by z-yarns in 3D composites. This crack arrest phenomena resulted in a reduction in inter-laminar crack lengths and a higher distribution of the micro-cracks throughout the 3D composite. The multi-step and cyclic loading tests are found to be useful in the monitoring of specimen behavior during short beam shear testing. The induced damage was quantified in terms of the loss of strength and stiffness during each loading cycle. It was found that while the 2D composites have higher damage resistance, the 3D composites have a higher damage tolerance.
\end{abstract}

(c) 2010 Elsevier Ltd. All rights reserved.

\section{Introduction}

Despite significant improvements in manufacturing processes, laminated composites continue to be susceptible to delamination under impact loads. Repeated loading of a damaged composite may cause the delamination cracks to propagate, leading to further degradation of strength. To reduce the propensity for delamination, toughened epoxies [1-3] were created using 2nd phase particles, e.g., polycarbonate [1] and rubber [2]. While the increase in fracture toughness for the epoxy was significant, the result was not as effective in the composite [2]. Another method to increase the delamination strength is the addition of through-thickness reinforcements [4] via z-pinning, stitching, and three-dimensional (3D) weaving [5,6]. 3D woven composites have been shown to exhibit superior properties in the through-thickness direction when compared to 2D laminated composites [7]. The mode-I and mode-II fracture toughness have also been shown to increase due to $z$-fiber reinforcement $[4,8,9]$, but under dynamic impact loading delamination continues to be a dominant damage mechanism $[8,10]$. Additional disadvantages associated with 3D woven composites include a decreased in-plane stiffness and strength as well as a loss of fatigue life [11]. When compared to stitched composites the in-plane compressive strength of 3D composites is found to be lower while the strain to failure is higher [12].

Numerous methods have been utilized to study the inter-laminar strength and the effect of $z$-fiber reinforcement on laminated

\footnotetext{
* Corresponding author. Tel.: +1 352392 7005; fax: +1 3523927303.

E-mail address: Subhash@ufl.edu (G. Subhash).
}

composites; (i) mode-I fracture toughness using double cantilever beam (DCB) test [13-16], (ii) mode-II fracture behavior using endnotch flexure (ENF) test [14,15], and (iii) short beam shear (SBS) test $[15,17,18]$ to determine the inter-laminar shear strength (ILSS). Other fixtures have also been designed to study the effect of combined loading [9]. In the first two methods, specimens are often manufactured to include Teflon ${ }^{\circledR}$ layers which act as precracks for DCB and ENF tests. However, SBS test specimens do not require pre-cracks and therefore may be easily prepared from a composite plate by sectioning the plate into the desired dimensions. The SBS test uses a three-point bending fixture to apply load to the composite specimen with a large height to length ratio. A schematic of the SBS test fixture is shown in Fig. 1. On either side of the central load a large shear stress is generated just beneath the top surface. Due to the short span relative to the thickness of the composite, the bending moment generated in the specimen is limited thus reducing the level of tensile and compressive bending stresses. The central punch creates a large contact stress which can cause local damage and lead to crushing of the specimen if the delamination strength is significantly high. To reduce this contact stress and create a more uniform load distribution, four-point [17] bending and five-point [19] bending fixtures have been adopted. Other limitations to the use of SBS testing include a greatly underestimated ILSS of the material $[17,20,21]$ due to the simplified assumption of shear flow equations which neglect the effect of concentrated load. Despite these disadvantages, SBS continues to be a useful test for qualitative comparison of the behavior of different material architectures as well as for quality control $[17,20]$. 


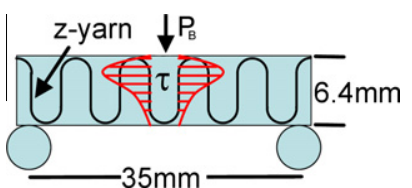

Fig. 1. Schematic of SBS test configuration.

Short beam shear testing may also be used in the study of impact behavior of composites. The large contact stresses created by the punch during SBS testing mimics the localized stresses generated during impact. Studies into the impact behavior of composites have shown that the large compressive and transverse shear stresses created beneath a projectile dominate the failure of the material $[22,23]$. Since the SBS test creates a similar state of stress, the results from these tests may be used to establish a baseline in which dynamic test results can be compared or to gain a fundamental understanding of damage evolution during impact.

In this manuscript we will present the results of SBS testing on four different woven composite architectures. Three different test procedures were used to evaluate the effect of z-yarns on the behavior of the composites. The induced damage is examined using optical microscopy and later utilized to assess the effectiveness of z-yarns on the delamination damage in each composite.

\section{Materials}

Several different woven composite plates measuring $150 \mathrm{~mm} \times 150 \mathrm{~mm}$ and approximately $6.4 \mathrm{~mm}$ thick were supplied by the US Army Research Laboratory, Aberdeen Proving Grounds, MD. The woven pre-forms were manufactured by t.e.a.m. Inc., Woonsocket, RI, using S-2 glass yarns of different linear densities. The pre-forms were consolidated using vacuum assisted resin transfer molding (VARTM) process with SC-15 epoxy. The orientation of the composite panels is defined such that the stuffer yarns are along the $x$-axis while the fill yarns are along the $y$-axis. The $z$-axis defines the thickness direction. The microstructure of each architecture was examined using optical microscopy. Small specimens were carefully sectioned using a Buehler ${ }^{\circledR}$, Lake Bluff, IL, low-speed diamond saw to minimize damage to the specimen. These specimens were then polished using a LECO $^{\circledR}$, St. Joseph, MI, auto-polisher following traditional metallographic techniques. Optical microscopic images were captured at low magnification detailing the weaving architecture along the $x-z$ plane. A schematic detailing the woven architecture and the optical images of the microstructure for all the composites are shown in Fig. 2. The thickness, the estimated total fiber volume fraction for each archi- tecture and the nominal percentage of z-yarns relative to the total fiber in the material are listed in Table 1. The following four composites were tested:

(1) A baseline 2D woven laminated composite (referred to as BL in the subsequent discussions) consisting of nine layers of plain woven S-2 glass fibers with an SC-15 epoxy matrix. The layers were stacked in a $\left[\left(0^{p w} / 45^{p w}\right)_{2} / \overline{0}^{p w}\right]_{s}$ sequence, symmetric about the mid-plane, where the superscript $p w$ refers to plain weave. Due to its common use, well-known architecture, and for the sake of brevity, its microstructure is not shown here.

(2) A 3\% orthogonally woven 3D composite (Fig. 2a), designated OG3, with a modified orthogonal weave and approximately $3 \%$ of the fiber volume consisting of z-yarns. This panel consists of five warp stuffer and six fill tows. A single warp weaver (or z-yarn) is woven around each column of fill tows. Two additional warp yarns weave the top and bottom fill tows. From the optical micrograph, shown in Fig. 2a, it is noted that the z-yarns do not follow a vertical straight path through the thickness of the panel, instead form an " $S$ " shaped curve. The 3D weaving also creates large pockets of matrix material within the composite structure as indicated in the figure.

(3) A $10 \%$ orthogonally woven 3D composite (Fig. 2b) designated as OG10, consisting of five warp stuffer and six fill tows with two z-yarns weaving each column of fill tows. These z-yarns weave from the top and bottom of the composite and cross at the midsection of the panel. The z-yarns account for approximately $10 \%$ of the total fiber volume.

(4) An angle interlock 3D woven composite (Fig. 2c), designated as AI, containing columns of fill yarns in a 3-2 alternating pattern. Six warp weaver yarns are woven through the thickness of the plate at an $18^{\circ}$ angle to the $x$-axis. There are no warp stuffer yarns present in this design. It was noted that large epoxy pockets were present in the structure similar to the orthogonal 3D woven composite. This weaving pattern contains the most undulation of all of the composite panels tested.

\section{Experimental procedure}

To determine the effect of z-yarn architecture and z-yarn volume fraction on the behavior of the composites, short beam shear (SBS) tests were performed as per ASTM D2344 [18]. This method uses a three-point bending fixture where the specimen is simply supported on two rollers with a fixed span of $35 \mathrm{~mm}$ and loaded with a central punch as shown in Fig. 1. The specimens are loaded

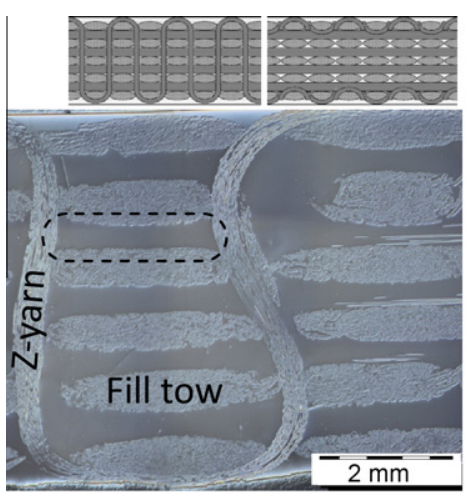

(a)

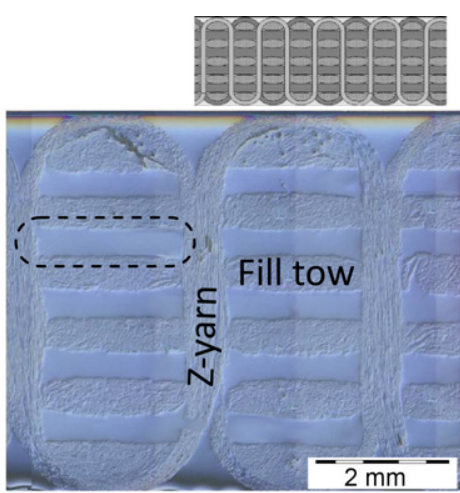

(b)

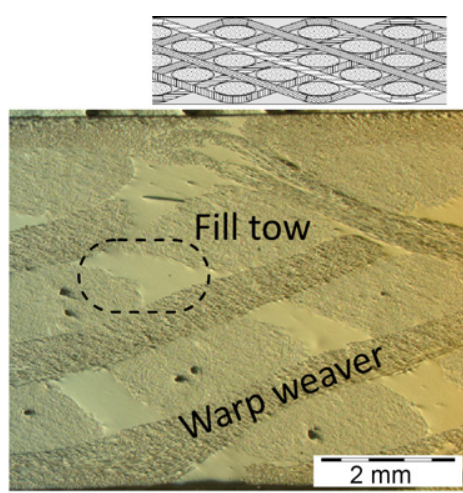

(c)

Fig. 2. Microstructure of: (a) OG3, (b) OG10 and (c) AI woven composites. Matrix pockets are indicated. 
Table 1

Summary of the composite specifications as well as ILSS from SBS tests.

\begin{tabular}{llcll}
\hline $\begin{array}{l}\text { Specimen } \\
(\mathrm{mm})\end{array}$ & Thickness & $\begin{array}{l}\text { z-yarn } \\
\text { fraction }^{\mathrm{a}}(\%)\end{array}$ & $\begin{array}{l}\text { Fiber volume } \\
\text { fraction }^{\mathrm{b}}(\%)\end{array}$ & ILSS (MPa) \\
\hline $\mathrm{BL}$ & 6.24 & 0 & 45 & $37.36 \pm 0.99$ \\
OG3 & 6.00 & 3 & 48 & $32.66 \pm 2.43$ \\
OG10 & 6.63 & 10 & 48 & $30.00 \pm 0.94$ \\
$\mathrm{AI}$ & 6.04 & $49^{\mathrm{c}}$ & 41 & $26.34 \pm 1.84$ \\
\hline
\end{tabular}

a $z$-yarn fraction represents nominal fraction relative to the total fiber volume.

b Fiber volume represents the fraction of fibers relative to the composite.

c AI specimen has a very high z-yarn fraction due to all warp tows being weavers (no warp stuffers).

using a hydraulic MTS ${ }^{\circledR}$, Eden Prairie, MN, testing machine using displacement control. The rate of loading, number of cycles, and total displacement are varied as described below. The anisotropic architecture of the 3D woven composites shown in Fig. 2 results in an unequal strength along the warp and fill directions. Initially tests were conducted along these two directions on each composite. For the sake of brevity only the results from specimens tested in the warp direction will be discussed as this direction represents the weakest and therefore the most likely direction of failure.

\subsection{Inter-laminar shear testing}

Several test specimens measuring $50.8 \mathrm{~mm} \times 25.4 \mathrm{~mm}$ were cut from each plate using a high-speed diamond saw. An average of five tests were performed on each composite. The applied load was measured using an inline static load cell. Both load and crosshead displacement were recorded during each test. The specimens were loaded at a rate of $1.0 \mathrm{~mm} / \mathrm{min}$ and each specimen was loaded up to a central displacement of $2 \mathrm{~mm}$ to determine the load required to initiate failure in the specimen as well as the post-failure behavior of the material. To compare the four composite structures the apparent ILSS is then calculated. Recall from above that this value does not necessarily represent the strength of the material but can be used to compare the relative performance of the different composites. The apparent ILSS is determined by the following formula [18]:

ILSS $=0.75 P_{B} / b d$

where $P_{B}$ is the peak load, $b$ is the width, and $d$ is the thickness of the specimen. After the tests, specimens were sectioned and polished for optical microscopic observation. A dye was applied to the surface to enhance the visibility of damage in the interior of the composite.

\subsection{Multi-step loading}

Specimens were repeatedly loaded to incrementally larger displacements using the short beam shear test method. Initial loading sequences were $0.5 \mathrm{~mm}$ and $1.0 \mathrm{~mm}$ displacements followed by increments of $0.25 \mathrm{~mm}$ until a maximum displacement of $2 \mathrm{~mm}$ was reached. For each loading step the rate of loading was $1 \mathrm{~mm} / \mathrm{min}$. The total input energy $\left(U_{t}\right)$ was determined by integrating the load displacement curve up to the final displacement. For each subsequent loading step the additional energy required for the additional displacement was added to the initial input energy. For the loading and subsequent reloading cycles the stiffness of the specimen was also calculated from the slope of the initial linear portion. For each cycle, a residual stiffness ratio was determined by dividing the stiffness from each reloading cycle by the initial stiffness. This residual stiffness ratio $\left(K_{\mathrm{r}}\right)$ for each reloading can then be plotted against the total energy from the previous cycles. Using this method it is possible to predict the behavior of each composite architecture, subjected to different input energies and determine the effect of $\mathrm{z}$-yarns on the residual stiffness.

\subsection{Cyclic loading}

Repeated loading can assist in determining the effect of z-yarns on the damage tolerance of the composite. For this purpose, short beam specimens were repeatedly loaded in displacement control for a selected number of cycles. Two sets of tests were performed: In the first test, each specimen was loaded in the initial linear regime (up to $0.8 \mathrm{~mm}$ deflection) for 250 cycles. The loading rate for this test was increased to $5 \mathrm{~mm} / \mathrm{min}$ to reduce the time required to perform each test. In the second set of tests each specimen was loaded at a rate of $5 \mathrm{~mm} / \mathrm{min}$ to a displacement just beyond the peak load determined from monotonic loading $(1.5 \mathrm{~mm}$ deflection) for 20 cycles. The load at the final displacement during each cycle was recorded during the test. This load was normalized after each subsequent cycle by the load determined from the first cycle. The rate at which the stiffness decreases in each cycle during the test provides insight into the effect of z-yarns on the propagation of damage in both the linear region and the region beyond the peak load.

\section{Results}

\subsection{Inter-laminar shear tests}

For each composite architecture tested, a load-displacement curve was selected which best represents the average of five

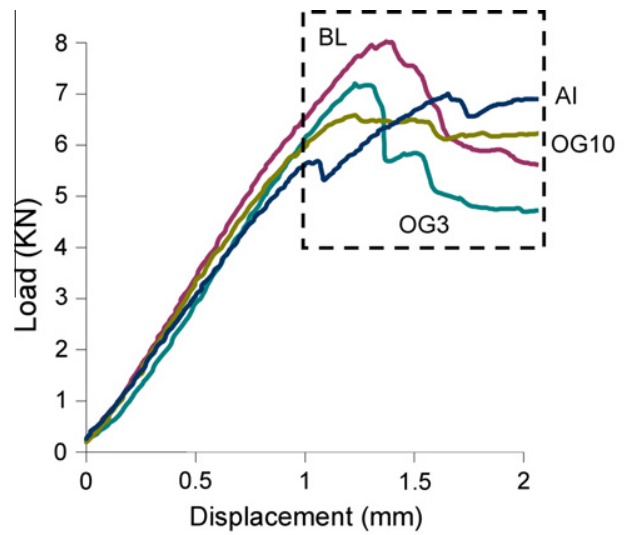

(a)

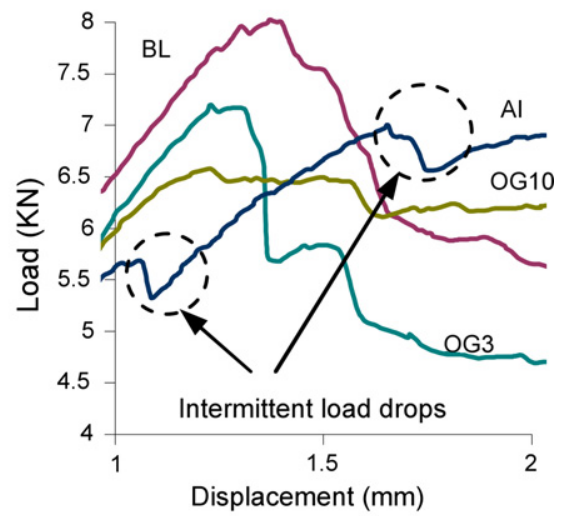

(b)

Fig. 3. (a) Representative load-displacement curves for all the composites and (b) magnified view of the post-elastic regime. 

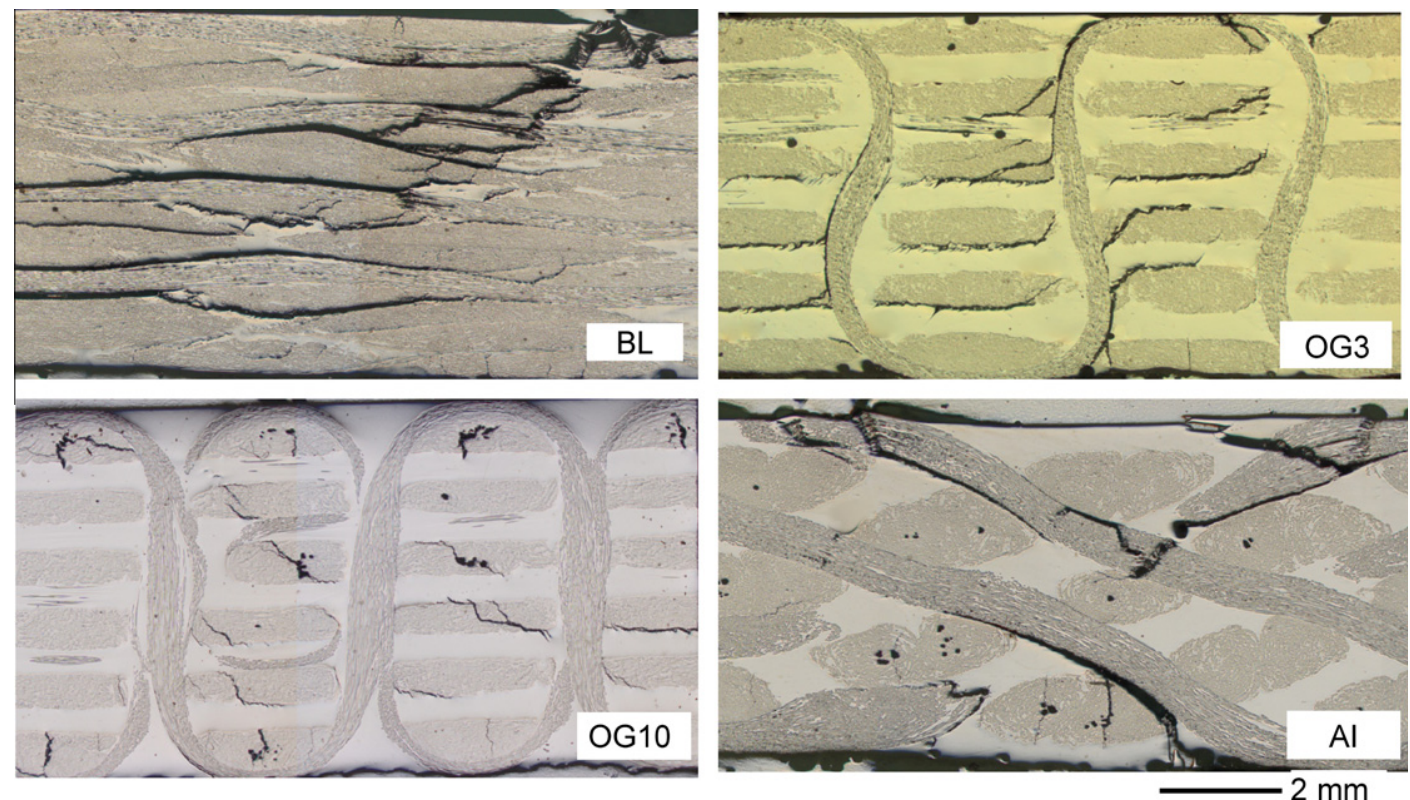

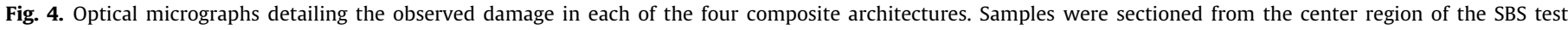
specimens.

separate test specimens. The typical load-displacement curves for each of the four materials are shown in Fig. 3a. The material response for each composite shows a nearly linear elastic trend during the early stage of loading. This continues until an apparent elastic limit is reached. At this point the behavior of the material follows one of three trends: the load decreases, remains constant, or increases.

Both the BL and OG3 composites showed a significant load decrease just beyond the peak load. The rate at which the load decreased then tapered off and the response began to plateau at a relatively constant load. The BL composite achieved the highest peak load among all the composites and maintained a higher load at $2 \mathrm{~mm}$ displacement compared to the OG3 composite.

The OG10 composite behaved much differently than the above two. The material reaches a peak load, slightly less than the OG3 composite, but then maintains that load over the remainder of the test. The load at the final displacement of $2 \mathrm{~mm}$ is slightly higher than the final load of the baseline material.

The AI composite reaches its elastic limit at the lowest load among the four composites. However, after this point the load continues to increase with intermittent small load drops which are accompanied by an audible crack. This architecture achieves the highest load at the final $2 \mathrm{~mm}$ displacement. For clarity, the load-displacement behavior of all the composites beyond the elastic limit is shown in detail in Fig 3b.

From the load histories, the apparent ILSS is calculated using Eq. (1). An average ILSS value is found from five tests for each composite and is reported in Table 1. It appears that as the percentage of $z$ yarn increased the apparent ILSS decreased. However the drop in strength after the initiation of failure at the maximum load decreases as the percentage of z-yarn increases as seen in Fig. 3b. Thus a higher load is achieved at the final $2 \mathrm{~mm}$ displacement for the composites with a higher volume fraction of z-yarns. This result would indicate that while the damage initiation may occur at a lower load, the damage tolerance of the material increases with the addition of z-yarns. In a study by Rao et al. [24] it has been shown that the in-plane properties decrease with the addition of 3D reinforcements when compared to equivalent unidirectional laminates. This decrease has been attributed to several factors including damage induced during the weaving process [25], large epoxy pockets, and the additional undulations (stress concentrations) created by the weaving architecture $[26,27]$. It is likely that these defects cause premature failure in the composite.

\subsection{Optical micrographs}

To assess the damage induced within the composites, optical micrographic investigations of sectioned specimens were undertaken. The induced damage for each composite is shown in Fig. 4. Three main types of damage modes were identified in each of the four composite architectures; localized damage beneath the punch, tow cracks along the bottom of the specimen, and delamination between the various tows and yarns. The localized damage is caused by the large stress concentration just beneath the central punch [20] resulting in crushing of the matrix and fiber damage in the tows. A tensile stress is generated at the bottom of the specimen due to the bending moment. This stress is significant enough to cause tensile cracks to form in both the tows parallel to the $y$ axis as well as in the matrix-rich pockets. However, the delamination damage presents itself differently in each composite. The extent, size and distribution of the delamination damage varied between each material architecture. Nevertheless, some general characteristics were noticed. Very little delamination was present at the center of the specimen (i.e., between the crushing zone at the top surface and tensile damage along the bottom), possibly due to the lack of a large shear stress in this region. None of the delamination cracks propagated through the entire sample to cause complete failure, i.e., each specimen remained intact and could continue to maintain a significant portion of its maximum load.

In the baseline (BL) composite, several large delamination cracks were observed to propagate on one side of the central contact region (Fig. 4). The delamination damage is quite significant leading to the sudden drop in load. The delamination cracks follow the undulation in the fiber tows of the 2D woven layers thus absorbing more energy. This type of delamination is consistent with damage reported by Padmanabhan [28].

In the OG3 composite delamination cracks appear along one side of the contact region between the stuffer and fill tows. These cracks propagate between the rows of z-yarns over a large 
distance. However, along the rows of z-yarns the delamination damage is limited and the cracks are arrested at the z-yarn reinforcement as shown in Fig. 4. On the other hand, in the OG10 composite the delamination damage appears as smaller cracks distributed along both sides of the central load. These cracks are seen between the stuffer and fill tows. As in the OG3 specimen, along the rows of z-yarns the delamination cracks do not cut the $z$-yarns to form larger cracks (i.e. the z-yarns are still intact). This mode of cracking indicates that the z-yarns act to prevent propagation of delamination damage. The uniform dispersion of damage within the specimen allows the composite to support the load even after failure initiates and hence the load remains relatively constant during the inelastic regime as seen in Fig. 3b.

The architecture of the AI composite specimens consists of the highest volume of warp weavers of all the 3D woven composites tested as indicated in Table 1 (see also Fig. 2c). Approximately half of the fiber volume consists of warp weavers which weave through the entire thickness of the plate. These undulations prevent delamination cracks from propagating parallel to the $x$-axis however they may also contribute to the lower strength of the material as discussed earlier. The damage observed in the optical micrograph in Fig. 4 reflects this behavior. The micrographs revealed limited local damage at the top and bottom of the specimen. It appears that a majority of the damage is caused by the concentrated load beneath the indenter. The delamination damage takes the form of small micro-cracks between the various weaving tows as well as within the fill tows parallel to the $y$-axis. This behavior is clearly reflected in the load-displacement curves. The small intermittent load drops in Fig. $3 \mathrm{~b}$ are likely associated with this damage.

A common observation for the BL and the OG3 specimens was that the damage was concentrated on one side of the center punch. It is inferred that the damage initiates at a critical flaw which reduces the local strength and results in a loss in stiffness. The drop in load observed in the BL and OG3 curves was presented in Fig. 3. Due to the drop in load the shear stress is also decreased which may prevent new delamination cracks from forming and allow additional damage to accumulate by propagating existing cracks. However the loss in stiffness due to this delamination damage prevents the initiation of cracks on the other side of the indenter. This results in most of the observed damage to form on one side of the indenter. This behavior was not observed in the OG10 and AI specimens. The delamination cracks are prevented from propagating by the presence of z-yarns and hence the drop in load was prevented which allows the delamination damage to propagate on both sides of the indenter.

From all the above observations it is inferred that as the percentage of through-thickness reinforcements increased, the mode of damage in the composite changed. In the absence of z-yarns, delamination cracks dominate the behavior and with the introduction of z-yarns the delamination damage is reduced, see Fig. 4. The damage becomes less concentrated and the cracks become shorter. As the z-yarn volume fraction is further increased the damage becomes more dispersed. This behavior is reflected in the load-displacement curves as well. When the delamination cracking is dominant, as in the 2D woven composite, the elastic limit is high but upon delamination the load drops sharply. On the other hand, when delamination cracking is prevented by the introduction of $z$ yarns the load after the elastic limit remained either constant or increased with displacement due to distributed damage within the composite.

\subsection{Multi-step loading}

The multi-step-loading curves for each specimen are shown in Fig. 5. The residual stiffness $\left(K_{\mathrm{r}}\right)$ from the unloading curves is plotted against the total energy $\left(U_{\mathrm{T}}\right)$ in Fig. 6 . Several observations can be made from these figures. It was noted that the overall response of the step-loading curves (shown in Fig. 5) follows similar trends noted in the monotonic curves (Fig. 3). Although there appears to be a slight loss in load between successive cycles, each loading cycle approaches the final load from the previous cycle. This indicates that extra damage induced by the multi-step loading sequence is
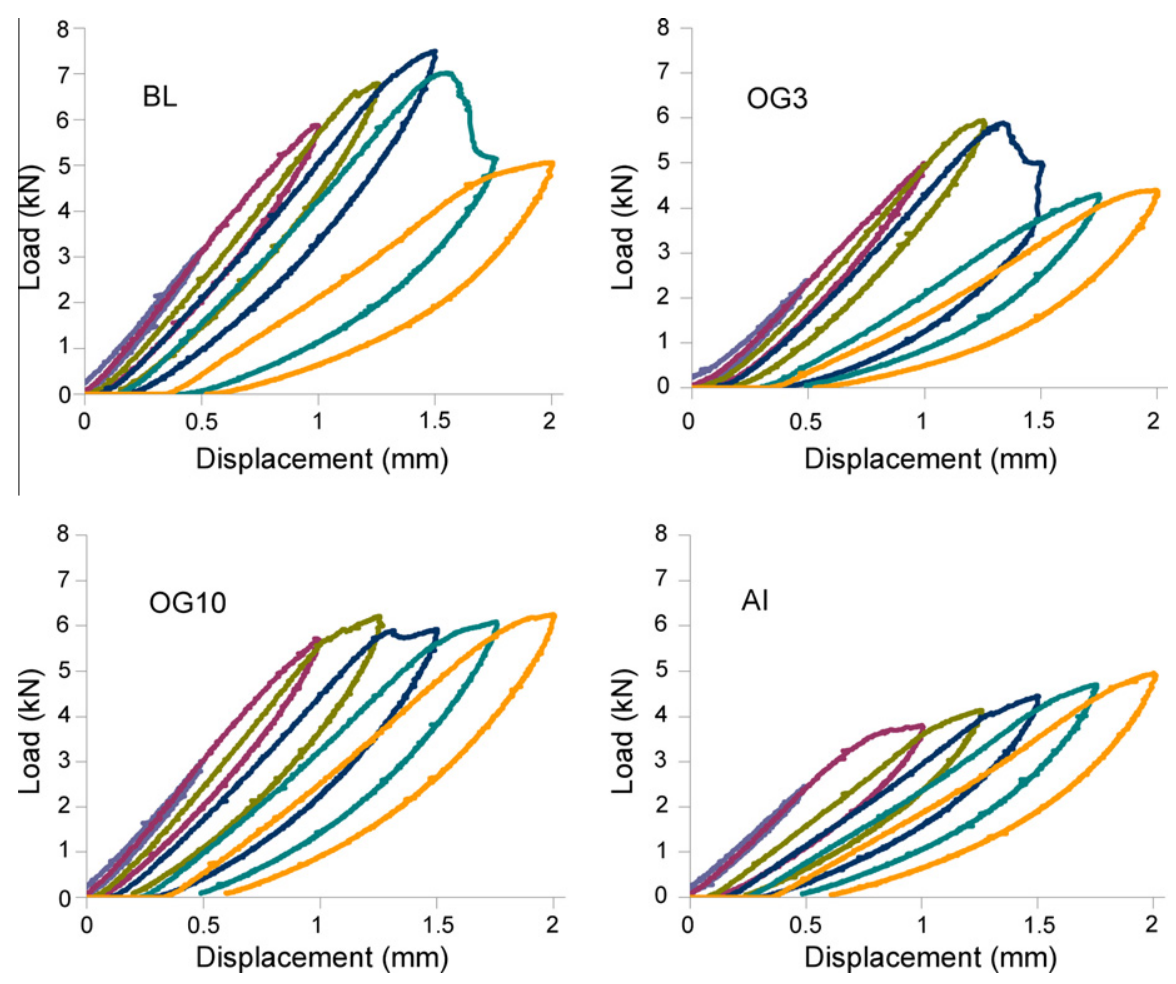

Fig. 5. Multi-step load-displacement curves for each composite architecture. 


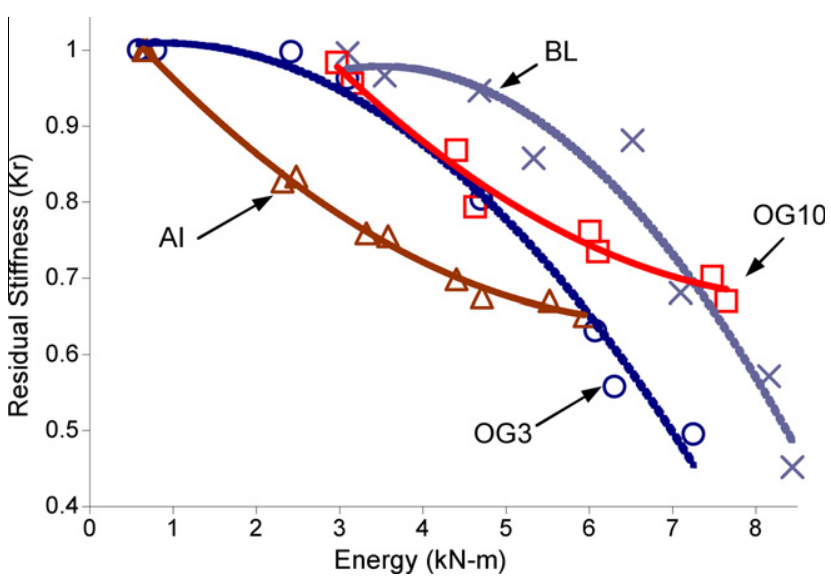

Fig. 6. Residual stiffness vs. energy from multi-step loading test results.

minimal and the response of the multi-step loading matches the response of the monotonic loading.

By examining the residual stiffness as a function of SBS energy, as shown in Fig. 6, it is possible to assess the effect of input energy on the induced damage. For each composite architecture, there is a limit in energy after which a significant loss in stiffness is observed. The baseline composite appears to reach the highest input energy before this loss occurs while the AI specimen has the lowest energy. The curves shown in Fig. 6 follow two distinct behaviors: after an initial loss in stiffness the rate of loss decreases as energy increases (BL and OG3) or the rate of loss continuously increases as the energy increases (OG10 and AI). This behavior coupled with the maximum energy before stiffness loss reveals two distinct modes of behavior: (i) the material is susceptible to damage initiation (i.e., low damage resistance) but resistant to damage propagation which indicates a high damage tolerance and (ii) the material has high damage resistance but has low damage tolerance. The OG10 and AI samples follow the first trend while the BL and OG3 samples follow the second. Although the baseline achieves a higher energy before stiffness begins to decrease, at higher energy levels the OG10 composite retains a greater portion of its stiffness. It appears that the presence of $z$-yarns reduces the damage resistance of the composite by initiating cracks while increasing the damage tolerance by preventing the cracks from propagating.

\subsection{Cyclical loading}

Load-displacement curves for BL and OG10 specimens subjected to high-cycle and low-cycle loading are shown in Fig. 7. It is seen that the peak load drops with each subsequent loading cycle indicating a loss in stiffness of the composite. The test results for both linear region as well as post-failure cyclic loading SBS testing are shown in Fig. 8. In each test the normalized stiffness of the specimen decreases gradually indicating progressive damage accumulation in each cycle within the specimen. In the linear regime (Fig. 8a), the strength reduction and hence the damage accumulation, is small and does not become significant until after 50 cycles are reached. In this regime the addition of z-yarns appears to initiate more damage leading to a larger reduction in strength for the

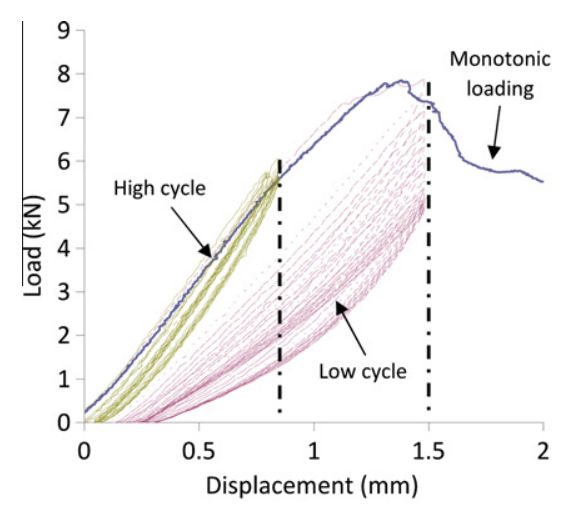

(a)

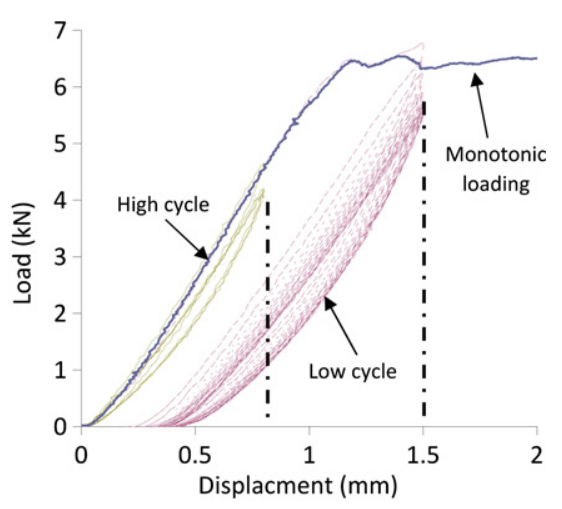

(b)

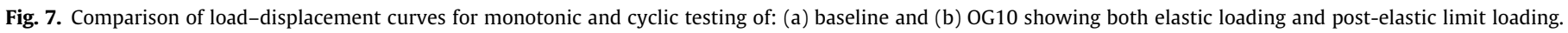

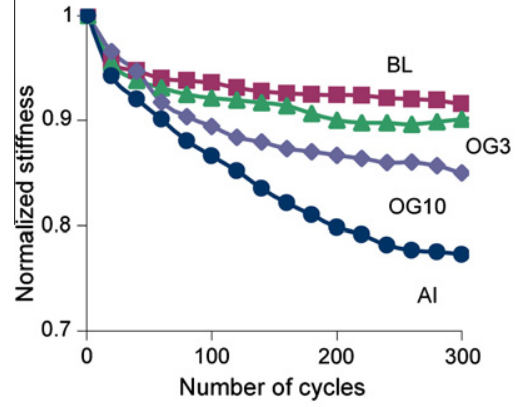

(a)

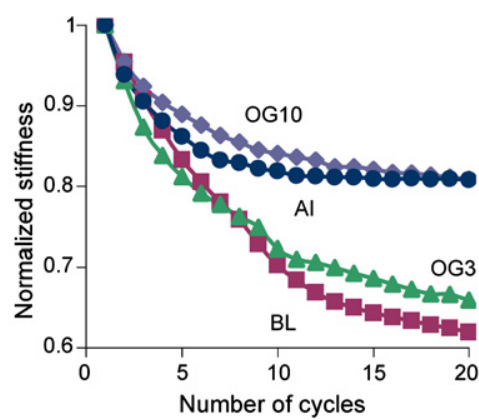

(b)

Fig. 8. Normalized stiffness vs. number of cycles for: (a) elastic loading and (b) post-elastic limit loading. 
OG10 and AI samples. This reduction is greater as the volume fraction of z-yarns increases. When cycled beyond the initiation of failure (Fig. 8b), the decrease in strength is more significant. After only 20 cycles the strength of the BL composite has decreased by at least $1 / 3$ of the strength of the virgin specimen. The OG3 specimens also show a significant drop in stiffness although slightly less than the BL. However, the OG10 and AI specimens still retained a significant amount of their strength. These results demonstrate the increase in the damage tolerance beyond failure through the addition of $\mathrm{z}$ yarns in 3D woven composites.

From the testing results discussed above it is apparent that the behavior of 3D woven composites subjected to SBS testing is quite complex. While the methods used in this research enhance our understanding of this complex behavior, additional methods may be necessary to fully characterize the materials tested. As mentioned above, the structure of the 3D woven composites leads to a large discrepancy in the ILSS when samples are tested in different directions. It is conceivable that a ratio could be established comparing the ILSS in both direction to predict how damage would propagate during panel level testing. Comparisons could then be made between the predicted damage and the actual damage.

The test results suggest that $3 \mathrm{D}$ woven composites suffer a reduction in strength compared to $2 \mathrm{D}$ laminated composites. As mentioned above this reduction has been associated with defects resulting from the 3D structure and weaving processes. However from the micrographs it is difficult to determine if delamination is originating from the defects described above. To fully understand the source and magnitude of the reduction in strength, more in-depth analysis may be required. Experiments could be conducted while using high speed photography to identify the initial source of damage, how damage progresses, and then identify the damage's effect on the load displacement curve. This may provide insight into how defects affect the strength of the composite.

\section{Conclusions}

Short beam shear testing of three 3D woven composites with different material architectures revealed a decrease in apparent inter-laminar shear strength when compared to a baseline plain woven laminated composite. As the fiber volume of z-yarns increased the inter-laminar shear strength continued to decrease. Optical microscopic observations of cross-sections of the test specimens revealed delamination damage, however, in the 3\% and $10 \%$ orthogonally woven specimens the propagation of delamination damage was arrested at the $z$-yarns. This allowed induced damage in the $10 \%$ orthogonal specimen to be more evenly distributed. This distributed damage has led to different post-elastic behavior for each of the composite architectures. While the base line and 3\% orthogonal specimens revealed a large drop in load after the elastic limit, the $10 \%$ orthogonal specimen maintained the failure load up to $2 \mathrm{~mm}$ deflection while the load continued to increase for $12^{\circ}$ angle interlock specimens. The distribution of damage and the ability to support a greater load in the post-elastic regime of the loaddeflection curve demonstrated that the damage tolerance of $3 \mathrm{D}$ woven composites is higher than 2D plain woven composites. Multi-step loading allowed for the stiffness of the specimens to be observed at several points during the short beam shear testing. By comparing the residual stiffness to the input energy it was possible to infer the amount of damage which had accumulated as the input energy increased. While the baseline material demonstrated a higher resistance to initial damage the stiffness began to drop sharply as the energy increased. However, in the $10 \%$ orthogonally woven specimen, after an initial drop in stiffness the rate of stiffness loss decreased as energy increased. During the repeated loading of the specimens, the strength of the material continued to decrease.
The presence of z-yarns allowed more damage to initiate under cyclic loading which reduced the strength of the material in the linear regime. In the post-failure regime, delamination cracks in the specimens continued to spread, however the presence of $z$ yarns hindered their propagation.

\section{Acknowledgements}

The authors sincerely acknowledge the Program Manager Dr. Bruce LaMattina of the United States Army Research Office for providing funding for this work (Grant Number W911NF-08-1-0120). The authors also acknowledge ARL for supplying the composite test panels.

\section{References}

[1] Varada Rajulu A, Babu Rao G, Ganga Devi L, Balaji PJ, He J, Zhang J. Interlaminar shear strength of polycarbonate-toughened epoxy composites reinforced with glass rovings. Adv Polym Technol 2003;22(4):373-7.

[2] Yan C, Xiao K, Ye L, Mai Y-W. Numerical and experimental studies on the fracture behavior of rubber-toughened epoxy in bulk specimen and laminated composites. J Mater Sci 2002;37(5):921-7.

[3] Reeder JR. Stitching vs. a toughened matrix: compression strength effects. J Compos Mater 1995;29(18):2464-87.

[4] Mouritz AP. Review of z-pinned composite laminates. Compos Part A: Appl Sci Manuf 2007;38(12):2383-97.

[5] Tong L, Mouritz A, Bannister M. 3D fibre reinforced polymer composites. Elsevier; 2002.

[6] Sharma SK, Sankar BV. Effects of through-the-thickness stitching on impact and interlaminar fracture properties of textile graphite/epoxy laminates. NASA contractor report; 1995 . p. 195042

[7] Mouritz AP, Bannister MK, Falzon PJ, Leong KH. Review of applications for advanced three-dimensional fibre textile composites. Compos Part A: Appl Sci Manuf 1999;30(12):1445-61.

[8] Mouritz AP. Ballistic impact and explosive blast resistance of stitched composites. Compos Part B: Eng 2001;32(5):431-9.

[9] Rys T, Sankar BV, Ifju PG. Investigation of fracture toughness of laminated stitched composites subjected to mixed mode loading. J Reinf Plast Compos; 2009. p. 0731684408099407.

[10] Walter TR, Subhash G, Sankar BV, Yen CF. Damage modes in 3D glass fiber epoxy woven composites under high rate of impact loading. Compos Part B: Eng 2009;40(6):584-9.

[11] Mouritz AP. Tensile fatigue properties of 3D composites with throughthickness reinforcement. Compos Sci Technol 2008;68(12):2503-10.

[12] Cox BN, Dadkhah MS, Inman RV, Morris WL, Zupon J. Mechanisms of compressive failure in 3D composites. Acta Metallurgica et Materialia 1992;40(12):3285-98

[13] Standard test method for mode I interlaminar fracture toughness of unidirectional fiber-reinforced polymer matrix composites. ASTM International, West Conshohocken, PA; ASTM Standard D5528-01.

[14] Tugrul Seyhan A, Tanoglu M, Schulte K. Mode I and mode II fracture toughness of E-glass non-crimp fabric/carbon nanotube (CNT) modified polymer based composites. Eng Fract Mech 2008;75(18):5151-62.

[15] Deng S, Ye L. Influence of fiber-matrix adhesion on mechanical properties of graphite/epoxy composites: II. Interlaminar fracture and inplane shear behavior. J Reinf Plast Compos 1999;18(11):1041-57.

[16] Guenon VA, Chou T-W, Gillespie Jr JW. Toughness properties of a threedimensional carbon-epoxy composite. J Mater Sci 1989;24(11):4168-75.

[17] Whitney JM, Browning CE. ON short-beam shear tests for composite materials. Exp Mech 1985;25(3):294-300.

[18] Standard test method for short-beam strength of polymer matrix composite materials and their laminates. ASTM International, West Conshohocken, PA, www.astm.org. ASTM Standard D2344/D2344M; 2000.

[19] Tao J, Sun CT, Arendt C, Brunner M. Interlaminar shear strength and fracture behavior in aged composite laminates. J Thermoplast Compos Mater 1998;11(2):124-32.

[20] Abali F, Pora A, Shivakumar K. Modified short beam shear test for measurement of interlaminar shear strength of composites. J Compos Mater 2003;37(5):453-64

[21] Rosselli F, Santare MH. Comparison of the short beam shear (SBS) and interlaminar shear device (ISD) tests. Compos Part A: Appl Sci Manuf 1997;28(6):587-94.

[22] Gama BA, Gillespie Jr JW. Punch shear based penetration model of ballistic impact of thick-section composites. Compos Struct 2008;86(4):356-69.

[23] Naik NK, Doshi AV. Ballistic impact behaviour of thick composites: parametric studies. Compos Struct 2008;82(3):447-64.

[24] Rao MP, Sankar BV, Subhash G. Effect of z-yarns on the stiffness and strength of three-dimensional woven composites. Compos Part B: Eng 2009;40(6):540-51 
[25] Lee L, Rudov-Clark S, Mouritz AP, Bannister MK, Herszberg I. Effect of weaving damage on the tensile properties of three-dimensional woven composites. Compos Struct 2002;57(1):405-13.

[26] Tan P, Tong L, Steven GP, Ishikawa T. Behavior of 3D orthogonal woven CFRP composites. Part I. Experimental investigation. Compos - Part A: Appl Science Manuf 2000;31(3):259-71.
[27] Cox BN, Dadkhah MS. Macroscopic elasticity of 3D woven composites. J Compos Mater 1995;29(6):785-819.

[28] Padmanabhan K. Interlaminar shear of woven fabric Kevlar-epoxy composites in three-point loading. Mater Sci Eng A 1995;A197(1):113-8. 